\title{
PERCEPÇÕES DE ESTUDANTES SOBRE O ENSINO DA LÍNGUA ESPANHOLA NA EDUCAÇÃO BÁSICA
}

\author{
Marcia Bianco ${ }^{1}$ \\ Andréa Andrade Alves ${ }^{2}$ \\ Marlene Zwierewicz ${ }^{3}$ \\ Rosani Hobold Duarte ${ }^{4}$
}

\section{INTRODUÇÃO}

A aprendizagem de línguas estrangeiras é uma possibilidade de aumentar a auto percepção do estudante como cidadão que interage com diferentes realidades, colaborando também para ampliar o desenvolvimento de competências que se tornam cada vez mais requisitadas no mundo globalizado. Independentemente da finalidade, "A aprendizagem de uma língua estrangeira deve garantir ao aluno seu engajamento discursivo, ou seja, a capacidade de se envolver e envolver outros no discurso". (BRASIL, 1998, p. 19).

Ao afirmar que o diálogo é uma espécie de ponte lançada entre o eu e os outros, Bakhtin (1986), implicitamente, lança um desafio às instituições educativas que trabalham com o ensino de línguas estrangeiras: o de contribuir para 0 desenvolvimento da competência comunicativa nos processos de ensino e aprendizagem. Não se trata, portanto, do ensino de gramática e de questões ortográficas isoladamente, mas de a língua estrangeira exercer sua função de abrir possibilidades para uma interação transfronteiriça.

Em relação às questões teóricas de língua estrangeira, a visão sociointeracionista de linguagem e aprendizagem defende a necessidade de ter como ponto de partida o próprio discurso, que, por sua vez, deve engajar-se na construção de um cidadão, sujeito histórico-cultural, capaz de cooperar socialmente a partir do seu entorno (BRASIL, 1998). Essa perspectiva remete à articulação entre linguagem em pensamento, referendada por Vygotsky (2005, p. 156-157) quando afirma que o '[...] pensamento não é simplesmente expresso em palavras; é por meio delas que ele passa a existir [...]" e converge com Pereira (2013, p. 52) ao

\footnotetext{
${ }^{1}$ Centro Universitário Barriga Verde - UNIBAVE. marcia.bianco@yahoo.com.br

${ }^{2}$ Centro Universitário Barriga Verde - UNIBAVE. andreaandradealves@hotmail.com

${ }^{3}$ Centro Universitário Barriga Verde - UNIBAVE. marlenezwie@yahoo.com.br

${ }^{4}$ Centro Universitário Barriga Verde - UNIBAVE. rosanihd@gmail.com
} 
defender que "[...] a linguagem atua não só como instrumento exterior de mediação, mas também, como formatadora de estruturas internas e do próprio processo de construção e reconstrução dessas estruturas. "

Essa construção e reconstrução são impulsionadas pela aprendizagem de uma língua estrangeira no contexto escolar enquanto também se aprofunda o domínio da língua materna. Essa condição é um direito de todo cidadão, defendido pela Lei de Diretrizes e Bases da Educação Nacional - Lei no 9394 (BRASIL, 1996) e pela Declaração Universal dos Direitos Linguísticos (UNESCO, 1996). Portanto, a escola não pode mais se omitir da responsabilidade de superar um ensino centrado no acesso às normas gramaticais e na sua respectiva memorização.

O papel educacional no ensino de língua estrangeira é contribuir para o desenvolvimento integral do indivíduo ao facilitar uma nova experiência de vida, que pode significar uma abertura para o mundo. Dessa forma, ajuda-se na construção e no cultivo de competências favoráveis à compreensão cultural, entre as quais se destaca a comunicativa, estimulando a formação para a cidadania e inserção no mercado de trabalho.

A competência comunicativa se diferencia do que foi definido por Chomsky como 'competência linguística', expressão que passou a ser veiculada em função das contribuições do autor que a definiu como "[...] conhecimento tácito, subjacente, abstrato da estrutura da língua, isto é, conhecimento que geralmente não está consciente ou disponível para um relato espontâneo, mas necessariamente implícito naquilo que o falante-ouvinte pode dizer. " (SOWEK, 1987, p. 24). É por meio desse conhecimento que uma pessoa pode compreender ou criar orações, independentemente de suas características socioculturais

A concepção de Chomsky posiciona-se muito próxima ao conhecimento do sistema da língua, ou seja, gramatical/ortográfico, o que comprova uma restrição na definição do autor. Para ampliar essa percepção, recorre-se a Hymes, já que sua interpretação, publicada em 1971, ultrapassa o domínio linguístico para atribuir importância à inclusão dos conceitos de propriedade e aceitabilidade. Essa capacidade de discernimento que Hymes concebe como a apropriação da competência comunicativa "[...] é alimentada pela experiência social, necessidades [...]" (SOWEK, 1987, p. 25).

A proposta de Chomsky subestima elementos pragmáticos e semânticos ao equiparar competência a conhecimento. Enquanto para Hymes o conhecimento é 
uma das partes da competência. A ampliação de conceito proposta por Hymes leva a optar pela competência comunicativa, pois entende-se que existem especificidades socioculturais, que interferem no uso da fala e da escrita, sendo que as variações se articulam com o contexto em que o falante-ouvinte se encontra (OLIVEIRA, 2007).

Já a competência comunicativa é uma das implicadas no ensino da língua estrangeira. Complementarmente, Macedo (2009) situa a escola como um lugar privilegiado, apesar de todas as suas dificuldades, para desenvolver competências, entre as quais está a comunicativa. Além da importância específica para a aprendizagem escolar, Macedo lembra que essa instituição prepara os estudantes para a vida em geral, pois é nela que geralmente se aprende a ler, escrever, contar, mas também, a raciocinar de forma mais profunda, ao explicar, resumir, observar, comparar e realizar outras atividades fundamentais para o desenvolvimento humano. Aproximando essa perspectiva às condições da realidade atual, a competência comunicativa precisa ser uma das preocupações nas práticas pedagógicas ao considerar-se as especificidades do mundo globalizado, no qual a interação entre diferentes culturas é cada vez mais dinâmica em função das possibilidades que as Tecnologias de Informação e Comunicação - TICs oferecem.

Para Durão (1998), com as medidas tomadas pelos países pertencentes ao Mercosul, tem-se um aumento considerável no interesse em aprender a língua espanhola. No caso específico de Santa Catarina, um dos estados brasileiros da região Sul, o Conselho Estadual de Educação (CEE), reunido em Sessão Plena, deliberou, por unanimidade dos presentes, a ampliação gradativa, a partir do ano de 2006, das condições para o ensino da língua espanhola (SANTA CATARINA, 2005)

Em âmbito nacional, a língua espanhola foi contemplada na Matriz Curricular do Ensino Fundamental no ano de 2007, período no qual se estipulou a obrigatoriedade desses estudos passarem de oito para nove anos de duração. Destaca-se ainda, na referida regulamentação, que a língua estrangeira passou a ser obrigatória a partir do $5^{\circ}$ ano, sendo oferecida, contudo, de acordo com a opção escolar (BRASIL, 2007). Portanto, a opção da língua estrangeira adotada pode condizer com as especificidades regionais.

Essa realidade justifica este estudo que precedeu a organização e criação de um programa para estimular as competências comunicativas no ensino da Língua Espanhola, desenvolvido com o apoio das TICs. A intenção de conhecer a 
percepção dos estudantes sobre a forma que o ensino da língua espanhola era desenvolvido, contribuiria com o levantamento de informações que seriam confrontadas com reflexões como as de Scott (1999), defensor de que a mudança de paradigma educacional pode ser, ao mesmo tempo, um desafio gratificante, especialmente quando se avaliam os resultados que produz, as contribuições de Xie Ke (2011), quando enfatiza o impacto que o intercâmbio sobre temas de unidades de currículo pode ter sobre a experiência de aprendizagem, bem como de Blin e Munro (2008), Bush e Mott (2009) e Ladyshewsky e Gardner (2008), ao observarem que as ferramentas de interação podem melhorar o desempenho escolar, possibilitando a criação de comunidades de aprendizagem. Nesse sentido, Pantoja e Huertas (2010) lembram que as TICs como uma ferramenta educacional não têm precedentes.

A pesquisa em sua originalidade, portanto, buscou avaliar condições implicadas no apoio do desenvolvimento de competências comunicativas em estudantes, a partir da aplicação de um programa apoiado pelo uso das TICs em função das condições que permitem, além de transmitir conhecimento, processar e difundir informações instantaneamente e a oportunidade de criar novo conhecimento colaborativo. O recorte realizado nesta síntese se restringe à percepção dos estudantes acerca dos conteúdos trabalhados, da aplicabilidade da Língua Espanhola na vida profissional e estratégias didáticas facilitadoras da aprendizagem antes da participação no programa.

\section{METODOLOGIA DA PESQUISA}

No levantamento dos dados sistematizados nesta pesquisa foi utilizado o método descritivo e a abordagem quantitativa. Na coleta de dados foi utilizado um questionário composto por quatro dimensões: (i) percepção dos estudantes acerca dos conteúdos trabalhados, (ii) aplicabilidade da língua espanhola na vida profissional, (iii) estratégias didáticas facilitadoras da aprendizagem e (iv) formas significativas para aprendizagem. $O$ instrumento foi elaborado com base nas contribuições de autores como Tobón (2006, p. 235) por destacar que a avaliação de competências implica em procedimentos "[...] para gerar valor (reconhecimento) em relação ao que as pessoas aprendem." Segundo ele, "[...] a avaliação consiste em 
um processo de retroalimentação mediante o qual os estudantes, os docentes, as instituições educativas e a sociedade obtêm informação qualitativa e quantitativa sobre o grau de aquisição, construção e desenvolvimento de competências. "

Além da validação semântica do instrumento, foi realizada a do construto. $\mathrm{Na}$ análise de fiabilidade, o questionário validado por docentes de uma Instituição de Ensino Superior - IES, localizada na região Sul do Estado de Santa Catarina, Brasil, atingiu um coeficiente de Alfa de Cronbach (consistência interna), de 0,788, condição que justifica a qualidade do instrumento.

O instrumento foi aplicado à amostra não probabilística acidental de $55,36 \%$ dos alunos, o que supõe 129 sujeitos do total de 233 que frequentavam turmas do $5^{\circ}$ ao $8^{\circ}$ ano de uma escola do município de Balneário Arroio do Silva Santa Catarina,

Brasil.

Apesar de alguns estudantes da amostra terem como origem países vizinhos, $89,1 \%$ responderam que não tiveram contato com a língua espanhola antes de ingressar nos anos finais do Ensino Fundamental.

\section{RESULTADOS E DISCUSSÃO}

Neste artigo é apresentada parte das perspectivas dos estudantes sobre três, das quatro dimensões implicadas na pesquisa. São elas: (i) percepção dos estudantes acerca dos conteúdos trabalhados, (ii) aplicabilidade da Língua Espanhola na vida profissional e (iii) estratégias didáticas facilitadoras da aprendizagem. Na sistematização, foram considerados os resultados da opção totalmente de acordo, apesar da escala Likert do instrumento ter sido formada por cinco pontos. Justifica-se essa opção pela diluição das outras respostas nas demais opções da escala, sendo que nenhuma delas ultrapassou os índices apresentados na sequência.

Quanto aos conteúdos, a maior parte dos estudantes destacou que os de maior interesse são aqueles que conseguem relacionar com situações práticas. Nesse sentido, vale lembrar o alerta de Morin (2010, p. 13) sobre a existência de uma inadequação "[...] cada vez mais ampla, profunda e grave entre os saberes separados, fragmentados, compartimentados entre disciplinas, e, por outro lado, realidades ou problemas cada vez [...] transversais, multidimensionais e transnacionais, globais, planetários." Um número significativo de estudantes também 
afirmou existir uma sistematização excessiva dos conteúdos e repetição nos diferentes anos.

Entre os resultados desta dimensão, destacam-se que: $45,2 \%$ dos estudantes concordaram totalmente que os conteúdos trabalhados nas aulas de espanhol não são interessantes, enquanto 41,5\% afirmaram que é mais fácil ler textos relacionados aos conteúdos que falar em espanhol. Também merece destaque o fato de que $56,3 \%$ concordarem totalmente sobre o interesse por textos que tratam de costumes e das tradições dos povos de língua espanhola.

Com relação à aplicabilidade da Língua Espanhola, as respostas destacaram a busca de empresas da região que trabalham com exportação de produtos por profissionais que falem fluentemente a referida língua. Nesse sentido, $68,8 \%$ concordaram totalmente com a insistência das empresas nessa busca. Além disso, 78,1\% afirmaram que existe grande procura de pessoas que dominam a língua espanhola para trabalhar em cursinhos.

Sobre as estratégias didáticas facilitadoras da aprendizagem, 65,5\% destacaram que estão totalmente de acordo com a importância do uso da internet, vídeos, materiais produzidos nos países que falam a língua espanhola e a discussão entre os docentes e os estudantes. Também evidenciaram que a aprendizagem é facilitada quando são realizados trabalhos lúdicos, como jogos variados, adivinhações, o que remete às reflexões de Rosa, Basso e Borges (2009, p. 31) de que "[...] é possível aprender com prazer, respondendo a desafios, solucionando problemas relacionados à própria vida [...]." Nessa mesma linha, os estudantes destacaram a importância do uso da biblioteca e que discussões sobre os acontecimentos nos países de língua espanhola influenciam positivamente na aprendizagem desta.

\section{CONSIDERAÇÕES FINAIS}

A aprendizagem de língua estrangeira é uma das condições que amplia possibilidades para a interação entre as pessoas e sua atuação profissional. Amparado pela legislação brasileira, essa aprendizagem pode ser favorecida com o uso de propostas que articulem os conteúdos curriculares e as demandas da realidade dos estudantes, estimulando a pertinência do ensino.

Nesse sentido, os resultados da pesquisa, que precedeu a elaboração de um programa para o ensino da Língua Espanhola no Ensino Fundamental, 
forneceram informações sobre a importância de envolver a realidade dos estudantes no desenvolvimento das aulas. Além de possibilitar a proposta que considere situações-problema, os resultados abrem possibilidades para incluir especificidades culturais da região em que estão inseridos, valorizando o desenvolvimento de competências comunicativas a partir da realidade local.

$\mathrm{Na}$ mesma direção, a percepção dos estudantes sobre a valorização de profissionais que dominam a referida língua em diferentes postos de trabalho, pode despertar a criação de estratégias que favoreçam o diálogo entre a escola e as empresas/instituições do entorno. Apesar da idade ainda precoce para parte dos estudantes, o fato de terem acesso às demandas do mundo do trabalho, pode contribuir para que encontrem sentido naquilo que desenvolvem no contexto escolar.

Já o uso de diferentes estratégias e recursos didáticos torna-se essencial para trabalhar a partir da realidade local e transitar globalmente. São condições como essas observadas na percepção dos estudantes que colaboraram para a criação do Programa Espanhol Criativo - PEC, aplicado posteriormente aos estudantes e avaliado por meio de uma pesquisa complementar, completando um processo sistemático de reflexão e ação, indispensável para o desenvolvimento de competências comunicativas.

\section{REFERÊNCIAS}

BLIN, F.; MUNRO, M. Why hasn't technology disrupted academics' teaching practices? Understanding resistance to change through the lens of activity theory. Computer Education, 2008, n. 50, v. 2, p. 475-490.

BUSH, M. D.; MOTT, J. D. The name assigned to the document by the author. This field may also contain sub-titles, series names, and report numbers. The Transformation of Learning with Technology: Learner- Centricity, Content and Tool Malleability and Network Effects. Educational Technology Publications, 2009, v. 49, n. 2, p. 3-20.

BRASIL. Lei de Diretrizes e Bases da Educação Nacional. Brasília: Ministério da Educação e Cultura, 1996.

. Secretaria de Educação Fundamental. PCN - Parâmetros Curriculares Nacionais: terceiro e quarto ciclos do Ensino Fundamental: língua estrangeira. Secretaria da Educação Fundamental. Brasília: MEC/SEF, 1998.

. Parecer CNE/CEB no 18/2007, aprovado em 8 de agosto de 2007. Brasilia: MEC/SEF, 2007. 
DURÃO, A. B.A. La enseñanza de español y de portugues en los países miembros del mercosur. Boletim/Centro de Letras e Ciências Humanas. Londrina: UEL, $n$. 34, p. 9-15, jan/jun. 1998.

LADYSHEWSKY, R. K.; GARDNER, P. Peer assisted learning and blogging: a strategy to promote reflective practice during clinical fieldwork. Australasian Journal of Educational Technology, v. 24, n. 3, p. 241-257, 2008.

MACEDO, E. Como a diferença passa do centro à margem nos currículos: o exemplo dos PCN, Educação \& Sociedade, Campinas, v. 29, n. 102, p. 55-78, jan/abr. 2009.

MORIN, E. A cabeça bem-feita: repensar a reformar, reformar o pensamento. Rio de Janeiro: Bertrand Brasil, 2010.

OLIVEIRA, M. H. C. de. Metodologia da Linguagem. 7. ed. São Paulo: Saraiva, 2007.

PANTOJA. A.; HUERTAS, A. Integración de las tic en la asignatura de Tecnología de educación secundaria. Pixel-Bit. Revista de Medios y Educación, v. 37, p. 225-237, 2010. Disponível em: < http://www.sav.us.es/pixelbit/pixelbit/articulos/n37/18.pdf>. Acesso em: 22 jun. 2016.

PEREIRA, P. G. Docência em Língua Inglesa nas Perspectivas Crítica e SócioHistórico-Cultural: as Experiências de Dois Alunos-Professores em Formação Inicial na Disciplina de Estágio Supervisionado. 144 f. (Dissertação de Mestrado). Universidade Federal de Goiás - Faculdade de Letras Pós-Graduação em Letras e Linguística, 2013.

ROSA, J.; BASSO, N. de S.; BORGES, R. M. R. Transdisciplinaridade: a natureza da educação científica. Porto Alegre: Edipucrs, 2007.

SANTA CATARINA. Lei no 11.161, de 05 de agosto de 2005, que dispõe sobre o ensino da Língua Espanhola. Disponível em: <fncee.com.br/wp-

content/uploads/2015/02/Língua-Estrangeira-238.pdf>. Acesso em: 22 jun. 2016.

SCOTT, G. Change matters: making a difference in education and training. St. Leonards: Allen \& Unwin, 2009.

SOWEK, O. Ensino de inglês pela abordagem comunicativa no $1^{\circ}$ e no $2^{\circ}$ grau. 1987. 140 f. Dissertação (Curso de Pós-Graduação, Área de Concentração Língua Inglesa, do Setor de Ciências Humanas, Letras e Artes) - Universidade Federal do Paraná, Curitiba, 1987.

TOBÓN, S. Las competencias en la educación superior. Políticas de calidad. Bogotá: ECOE, 2006. 
UNESCO. Declaração Universal dos Direitos Linguísticos. Barcelona. 1996. Disponível em:

<http://documentosrtl.wikispaces.com/file/view/Declara\%C3\%A7\%C3\%A30+Univers al+dos+Direitos+Lingu\%C3\%ADsticos. pdf>. Acesso em: 22 jun. 2016.

VYGOTSKY, L. S. Pensamento e linguagem. 3. ed. São Paulo: Martins Fontes, 2005.

$\mathrm{XIE}, \mathrm{K}$; $\mathrm{KE}, \mathrm{F}$. The role of students' motivation in peermoderated asynchronous online discussions. British Journal of Educational Technology, v. 42, n. 6, p. 916930, 2011. 